\title{
PREVALENCE OF CROSSBITE IN SCHOOL CHILDREN OF SUNDAR INDUSTRIAL STATE AND RAIWIND, LAHORE: AN EPIDEMIOLOGICAL STUDY
}

\author{
Rabia Tabassuma, Nazish Amjad ${ }^{b}$, Faiza Malikc, Munazza Saleem ${ }^{d}$ \\ aSenior lecturer, Department of Orthodontics, University Medical and Dental College, Faisalabad. \\ ${ }^{b}$ Assistant Professor, Department of Orthodontics, Dental College HITEC-IMS, Taxila. \\ 'Assistant Professor and Head, Department of Orthodontics, Sharif Medical and Dental College, \\ Lahore. \\ ${ }^{\mathrm{d} D e m o n s t r a t o r, ~ D e p a r t m e n t ~ o f ~ O r t h o d o n t i c s, ~ U n i v e r s i t y ~ M e d i c a l ~ a n d ~ D e n t a l ~ C o l l e g e, ~ F a i s a l a b a d . ~}$
}

\section{ABSTRACT:}

BACKGROUND \& OBJECTIVE: Crossbite is a commonly occurring malocclusion. It may be anterior or posterior, and it may occur either unilaterally or bilaterally. This study determined the prevalence of crossbite in children of different schools of Sundar industrial state and Raiwind.

METHODOLOGY: Nine hundred (428 male and 472 female) children of various schools of Raiwind and Sundar Industrial State, Lahore, were examined. Information regarding age, sex, and crossbite were noted. The recorded data were analyzed by using SPSS version 20. Frequency distribution was used for the descriptive analysis. Statistical level of significance using student's t-test was $p<0.05$.

RESULTS: Out of 900 children, $117(13 \%)$ were noted to have at least one tooth in crossbite, which was more frequent in permanent (13.2\%) than in mixed dentition $(12.3 \%)$. The prevalence of crossbite was slightly greater in female subjects $(16.1 \%)$ than in male subjects $(9.1 \%)$. Crossbite was seen more frequently in the posterior (6.3\%) than the anterior region(5.9\%). Combined anterior and posterior crossbite was found in $7(0.8 \%)$ children. Unilateral crossbite on the left side was found to be more frequent $(6.6 \%)$ than on the right side $(4.6 \%)$, and the bilateral crossbite was found to be in $1.9 \%$ of children. Buccal crossbite was more prevalent $(6.8 \%)$ than lingual crossbite $(5.8 \%)$. Combined lingual and buccal crossbite was found to be in $0.4 \%$ of children.

CONCLUSION: Crossbite is a frequently occurring malocclusion in school children of Sundar industrial state and Raiwind, Lahore. Posterior crossbite is more prevalent than anterior crossbite.

KEYWORDS: Crossbite, Malocclusion, Prevalence, Epidemiological study.

\section{How to cite this:}

doi: https://doi.org/10.37723/jumdc.v12i2.526

Tabassum R, Amjad N, Malik F, Munazza S.PREVALENCE OF CROSSBITE IN SCHOOL CHILDREN OF SUNDAR INDUSTRIAL STATE AND RAIWIND, LAHORE: AN EPIDEMIOLOGICAL STUDY. jumdc. $2021 ; 12(2): 98-102$.

doi: https://doi.org/10.37723/jumdc.v12i2.526

This is an Open Access article distributed under the terms of the Creative Commons Attribution License (http://creativecommons.org/licenses/by/4.0), which permits unrestricted use, distribution, and reproduction in any medium provided the original work is properly cited. 


\section{INTRODUCTION:}

Malocclusion significantly affects the psychological and social well-being of the children. Well-aligned teeth and a pleasing smile reflect the positive status and well-being ${ }^{[1]}$. Malocclusion is defined as a deviation from normal occlusion, andit is associatedwith the person's complete physical well-being and quality of life ${ }^{[2]}$.

A crossbite is a type of malocclusion in which maxillary and mandibular teeth have abnormal labiolingual or buccolingual relationships when they are in occlusion. According to location, it can be classified as an anterior or posterior crossbite. It can also be classified to identify whether one tooth or multiple teeth are involved ${ }^{[3]}$.

According to previous literature, in Nigeria, the prevalence was stated to range from $2 \%$ to $16 \%$. Crossbite has been found to be more prevalent in females as compared to males, according to the previous reports ${ }^{[4]}$.

Depending on the inclusion of edge-to-edge relationship in the data and the children's ethnicity, the prevalence of anterior crossbites was reported to vary between $2.2 \%$ to $12 \%$. $36 \%$ of the patients having anterior crossbite also exhibit functional mandibular shift ${ }^{[5]}$.

Anterior crossbite is a commonly occurring malocclusion, and it ismostly seen in early mixed dentition. It is the term used to describe an abnormal labiolingual relationship between one or more maxillary and mandibular incisor teeth in which maxillary incisors are placed lingual to mandibular incisors when both jaws are in centric occlusion ${ }^{[6]}$.

According to the etiology and clinical appearance, there are three important types of anterior crossbite, dental anterior crossbite, anterior skeletal crossbite, and functional anterior crossbite. In a dental anterior crossbite, usually, a single tooth is involved instead of multiple teeth, and it is due to the abnormal labiolingual position of teeth. Skeletal anterior crossbite arises due to either genetic or hereditary influence or discrepancy in the size of maxilla (retrognathic) or mandible (prognathic). Functional anterior crossbite is a type of pseudoclass III malocclusion in which the mandible is postured forward from its true centric position ${ }^{[6]}$. Anterior crossbite is considered an orthodontic emergency. Its treatment during mixed dentition is recommended because it can negatively affect the maxillary jaw's growth and development. It can also cause temporal and masseter muscle activity problems, which can enhance the risk of temporomandibular disorders with growing age $^{[7]}$.

Corresponding Author:

Dr. Rabia Tabassum

Senior lecturer, Department of

Orthodontics, University Medical and Dental

College, Faisalabad.

Email: drrabiatabassum1986@hotmail.com

Posterior crossbite is defined as an inadequate transverse relationship of maxillary and mandibular teeth. It is one of the most frequently occurring malocclusionin the primary and early mixed dentition, and its reported prevalence is $8 \%$ to $22 \%{ }^{[5]}$. The unilateral crossbite with the functional shift of the mandible towards the crossbite side is the most common type of posterior crossbite ${ }^{[8]}$.

A posterior crossbite can be a result of dental or skeletal abnormalities or a combination of the two. Posterior dental crossbite is due to malpositioned posterior teeth. Posterior skeletal crossbite is due to a discrepancy between the width of the maxilla and mandible. The posterior crossbite can also be due to prolonged retention or premature loss of primary teeth, and ectopic eruption of the mandibular first molar, prolonged thumb or finger sucking habit, mouth breathing or cleft palate, and improperly functioning temporomandibular joints ${ }^{[5]}$.

An untreated posteriorcrossbite in primary or mixed dentition can transfer to permanent dentition. It can also have prolonged effects on the growth and development of jaws and inclination and periodontal health of teeth.In the majority of cases, a unilateral posterior crossbite can cause a mandibular shift with midline deviation. This can cause masticatorymuscles and temporomandibular joint disorderdue to prolonged stress on oral and facialstructures ${ }^{[7]}$.

The objective of this studywas to determine the prevalence of crossbite in school children of Sundar industrial state and Raiwind in Lahore, Pakistan. 


\section{METHODOLOGY:}

Permission was taken from the ethical committee of University Medical and Dental College Faisalabad. This was a cross-sectional study.A total of 900 children at 5 schools of Raiwind and Sundar Industrial State, Lahore, were examined according to a simple random sampling technique to evaluate crossbite. Children having previous orthodontic treatment and complex craniofacial deformities and syndromes were excluded from the study.

Crossbite was classified as anterior or posterior, unilateral or bilateral. Anterior crossbite is present when maxillary incisors are placed lingual to mandibular incisors when both jaws are in centric occlusion. Posterior crossbiteis present when the buccal cusps of maxillary premolars or molars occlude lingual to mandibular posterior teeth. Crossbite is classified as unilateral when it is present only on one side of the midline, either right or left, and bilateral when present on both sides. Crossbite is classified as buccal when maxillary posterior teeth occlude entirely on the buccal aspect of the mandibular posterior teeth and lingual when maxillary posterior teeth occlude entirely on the lingual aspect of the mandibular posterior teeth.

The recorded data were analyzed by using SPSS version 20. Frequency distribution was used for the descriptive analysis. Statistical level of significance using chi-square test and single sample t-test was $p<0.001$

\section{RESULTS:}

The chronological age range of recorded subjects was 6-18 years with a mean age of 11.93 (SD $=2.524$ ). The sex distribution of the sample is given in Table-I.

Out of 900 children $(\mathrm{N}=900) 117(13 \%)$ were noted to have at least one tooth in crossbite. Out of 117 children with a crossbite,39 were males, and 77 were females. The difference was statistically significant with $p=0.001$ (Table II). Crossbite was found to be slightly more frequent in permanent dentition as compared to the mixed dentition. However, the difference was not statistically significant $(p=0.725)$ (Table III). The occurrence of anterior crossbite is less frequent than posterior crossbite $(p=0.588)$. The difference was not statistically significant. Children having combined anterior and posterior crossbite constituted $(0.8 \%$ ) (Table-IV). Unilateral crossbite was found to be more frequent on the left quadrant than on the right quadrant $(p=0.609)$. The difference was not significant. The frequency of children with bilateral crossbite was found tobe $(1.9 \%)$ (Table-IV).

Table-I: Gender distribution of the sample.

\begin{tabular}{|c|c|}
\hline Gender & N (\%) \\
\hline Males & $428(47.6)$ \\
\hline Females & $472(52.4)$ \\
\hline Total & $900(100)$ \\
\hline
\end{tabular}

Table-II: Prevalence of crossbite in males and females.

\begin{tabular}{|c|c|c|c|c|}
\hline & Normal & Crossbite & Total & p-value \\
\hline Males & 389 & 39 & 428 & $<0.001$ \\
\cline { 1 - 3 } Females & 395 & 77 & 472 & \\
\hline Total & 784 & 116 & 900 & \\
\hline
\end{tabular}

Probability value by using chi-square test

Table-III: Prevalence of crossbite in mixed and permanent dentition.

\begin{tabular}{|c|c|c|c|c|}
\hline & Normal & Crossbite & Total & p-value \\
\hline Mixed dentition & 304 & 43 & 347 & \multirow{2}{*}{0.725} \\
\hline Permanent dentition & 480 & 73 & 553 & \\
\hline
\end{tabular}

Probabilityvalue by using chi-square test 
Buccal crossbite was more prevalent than lingual crossbite. However, the difference was not

statistically significant $(p=0.725)$ Table-V.

Table-IV: Prevalence of anterior and posterior crossbite.

\begin{tabular}{|c|c|c|c|}
\hline & N (\%) & Valid percent & \multirow{2}{*}{ p-value } \\
\hline Anterior & $53(5.9)$ & 45.3 & \multirow{2}{*}{0.136} \\
\cline { 1 - 3 } Posterior & $57(6.3)$ & 48.7 & \multirow{2}{*}{0.085} \\
\hline Both & $7(0.8)$ & 6 & \multirow{2}{*}{0.0} \\
\hline Unilateral right & $41(4.6)$ & 50.4 & \\
\hline Unilateral left & $59(6.6)$ & 14.5 & \\
\hline
\end{tabular}

Probability value by using single sample t-test.

Table V: Prevalence of buccal and lingual crossbite.

\begin{tabular}{|c|c|c|c|}
\hline & Crossbite & Percent & p-value \\
\hline Buccal & 61 & $6.8 \%$ & \multirow{2}{*}{0.158} \\
\hline Lingual & 52 & $5.8 \%$ & \\
\hline Both & 4 & $0.4 \%$ & \\
\hline
\end{tabular}

Probability value by using single sample t-test.

In an anterior dental crossbite, mostly a single incisor is involved, which is considered an easy orthodontic problem ${ }^{[4]}$. This type of crossbite is usually associated with gingival recession resulting in an increased crown length of that tooth. Anterior crossbite may also cause a functional shift of the mandible resulting in pseudo-class III malocclusion, so it should be treated as soon as possible [5]

The prevalence of anterior crossbite in the present study is $5.9 \%$ which is more than another study carried out in Karachi in which its prevalence was $3.1 \%{ }^{[12]}$.

The present study shows that the prevalence of anterior crossbite is less as compared to a posterior crossbite. This finding does not match with the results seen in the general Nigerian population in which anterior crossbite is more prevalent as compared to posterior crossbite ${ }^{[13]}$. But this finding of more frequent posterior crossbite is similar to the finding of the study carried out in Saudi Arabia. The prevalence of posterior crossbite was $9.4 \%$, and the anterior crossbite was $4.8 \%{ }^{[14]}$. Another study of
Bangladesh ${ }^{[8]}$ prevalence of posterior crossbite was $36.3 \%$, and the anterior crossbite was $30 \%$. These higher values are due to the fact that the study was performed on orthodontic patients.

Unilateral posterior crossbite is more prevalent on the left side in the present study, while according to the results of another study carried out in Karachi, crossbite was more prevalent on the right side ${ }^{[12]}$. According to the present study results, crossbite is more frequent in females than the males. This finding is comparable to the findings of other studies carried out in other countries $^{[4,7]}$.

Crossbite can be treated in two ways. Dental crossbite can be treated by repositioning individual teeth by using removable or fixed appliances, and skeletal crossbite can be treated by facemask therapy in growing individuals or orthognathic surgery in adult patients ${ }^{[15]}$.

In the present study, the prevalence of crossbite was found out in school children of limited areas of Lahore. Therefore, it is desirable to find out the prevalence of crossbite in other areas of Lahore as well. 


\section{CONCLUSION:}

Crossbite is a frequently occurring anomaly in the Pakistani population which is more frequent in female patientsthan male patients.Posterior crossbite is more frequent than anterior crossbite. Among the posterior crossbite, unliteral crossbite on the left side is more prevalent than on the right side.

ACKNOWLEDGEMENT: None.. CONFLICT OF INTEREST: None GRANT SUPPORT \& FINANCIAL DISCLOSURE: None

\section{REFERENCES:}

1. Reddy NV, Reddy MA, Chandana N, Karthik $T$, Daneswari V, Niharika P. The prevalence of malocclusion among 10-12-yearold schoolchildren in Khammam district, Telangana: An epidemiological study. International Journal of Pedodontic Rehabilitation . $2019 ; 4$ ( 2):65-70. Doi :10.4103/ijpr.ijpr_5_19

2. Rapeepattana S, Thearmontree A, Suntoknlohanakul $S$. The prevalence of orthodontic treatment need and malocclusion problems in 8-9-year-old schoolchildren. A study in the south of Thailand. APOS Trends in Orthodontics.2019;9(2):99-104. Doi:10.25259/APOS-3-2019

3. Shruthi D, Ganesh J. Prevalence of crossbite in primary dentition. Drug Invention Today.2019;12(1):215-218.

4. Dacosta OO, Utomi IL. A Clinical Review of Crossbite in an Orthodontic Population. West African Journal of Medicine. 2011;30(1):2428. Doi: 10.4314/wajm.v.30i1.69880

5. Wiedel AP, Bondemark L. Stability of anterior Crossbite correction. A randomized controlled trial with a 2 year follow- up. Angle Orthodontist.2015;85(2):189-195. Doi: 10.2319/041114-266.1

6. Vithanaarachchi SN, Nawarathana LS. Prevalence of anterior crossbite in preadolescent orthodontic patients attending an orthodontic clinic. Ceylon Medical Journal.2017;62:189-192.Doi: 10.4038/cmj. v62i3.8523

7. Saqib N, Saad A, Waheed HM. Prevalence of crossbite in orthodontic patients. Pakistan Oral and Dental Journal. 2009; 29(2):279280.
8. Chowdhury MS, Sultana N, Naim M, Nashrin T, Nahar L. Prevalence of Cross Bite among the Orthodontic Patients at a Dental Unit of Bangladesh. Journal of National Institute of Neurosciences Bangladesh. 2019;5(2):167171. Doi:10.3329/jninb.v5i2.43024

9. Sundarewaran S, Kizhakool P. Prevalence and gender distribution of malocclusion among 13-15-year-old adolescents of Kerala, South India. Indian Journal of Dental Research.2019;30(3):455-461.Doi:10.4103/ ijdr.IJDR_801_16

10. Anniceleda SA, Gustavo HG, Moara D, Maria BDG. Posterior Crossbite and Functional Changes. Angle Orthodontist. 2009;79(2):380386. Doi:10.2319/030708-137.1

11. Gul E, Fida M. Pattern of malocclusion in orthodontic patients; A hospital based study. Journal of Ayub Medical College.2008; 20(1):43-47.

12. Nazir R, Amanat N, Rizvi KF. Pattern, prevalence and severity of malocclusion among university students. Journal of Pakistan Dental Association.2013;22(1):13-18

13. DaCosta OO. A survey of occlusal anomalies in 1028 school children in Kaduna, Northern Nigeria. African Dental Journal.1998; 12: 8-12.

14. Gudipaneni RK, Aldahmeshi RF, Patil SR, Alam MK. The prevalence of malocclusion and theneed for orthodontic treatment amongadolescents in the northern border region of Saudi Arabia: An epidemiological study. BMC Oral Health.2018;18(1):1-6. Doi:10.1186/s12903-018-0476-8

15. Sayar G, Kilinic DD. Rapid maxillary expansion outcomes according to midpalatal suture maturation levels. Progress in Orthodontics.2019;20(1):1-7 Doi: 10.1186/ s40510-019-02789-9.

\section{Author's Contribution:}

Rabia Tabassum: Designed the study, collected the data, did the complete write up of the article. Nazish Amjad: Helped in the statistics of the article and analysis of the results.

Faiza Malik: Supervised the research, reviewed the article, helped in the write up.

Munazza Saleem: Helped in data collection.

Submitted for Publication: 02-12-2020

Accepted after revision: 09-04-2021 